\title{
DETEKSI CITRA WAJAH DENGAN METODE HAAR FEATURE SELECTION
}

\author{
Nahdi Saubari \\ Program Studi Informatika, Universitas Muhammadiyah Banjarmasin \\ Jl. Gubernur Syarkawi, Kabupaten Barito Kuala, 70552, Indonesia. \\ e-mail: nahdi.vfp@gmail.com
}

\begin{abstract}
ABSTRAK
Banyak sistem biometrik yang dapat diterapkan pada proses verifikasi citra, tapi kebanyakan menggunakan teknik autentifikasi yang sama. Proses untuk pendeteksian citra wajah manusia dapat dilakukan secara digital dengan menggunakan komputer dan merupakan salah satu domain dalam aplikasi computer vision. Salah satu metode yang digunakan adalah metode haarfeature selection yang merupakan bagian dari metote Viola-Jones. Penelitian ini bertujuan mengetahui seberapa jauh metode haar feature selection tersebut dapat digunakan untuk deteksi wajah. Metode yang digunakan adalah eksperimen dengan mengekstraksi ciri pada wajah manusia. Hasil yang diperoleh dari ujicoba yang dilakukan terbukti bahwa metode Haar Feature selection dapat digunakan untuk mendeteksi citra wajah dengan akurasi 91,34\% dalam waktu 0,61 detik dengan pada jarak $55 \mathrm{~cm}$ dari kamera dengan ukuran $120 x 190$ piksel.
\end{abstract}

Kata Kunci:Biometrik, Computer vision, Deteksi wajah, Haar feature selection.

\section{ABSTRACT}

Many biometric systems can be applied to the image verification process, but most use the same authentication techniques. The process for detecting human face can be done digitally using a computer as one of the domains in computer vision applications. One of the method namely the haar feature selection method which is part of the Viola-Jones method. This study aimed to find out how far the haar method feature selection can be used for face detection. The method used was an experiment by extracting features on the human face. The results obtained from the tests proved that the Haar feature selection method can be used to detect facial images with an accuracy of $91.34 \%$ in 0.61 seconds with a distance of $55 \mathrm{~cm}$ from a camera measuring $120 x 190$ pixels.

Keywords: Biometrics, Computer vision, Face detection, Haar feature selection.

\section{PENDAhUluan}

$\mathrm{D}$ ETEKSI wajah memiliki dua klasifikasi, yaitu wajah atau non wajah. Setiap wajah yang terdeteksi akan diproses secara unik kedalam basis data dengan proses identifikasi dan verifikasi. Masalah yang sering terjadi dalam proses pendeteksian wajah adalah pada pose dan faktor pencahayaan. Banyak sistem biometrik dapat diterapkan pada proses verifikasi citra, tapi semuanya kebanyakan menggunakan teknik autentifikasi yang sama [1].

Proses untuk pendeteksian wajah dilakukan secara digital dengan menggunakan komputer dan merupakan salah satu domain dalam aplikasi computer vision. Deteksi wajah didasarkan pada identifikasi dan menemukan lokasi citra wajah manusia dalam citra terlepas dari ukuran, posisi dan kondisi [2].

Pendeteksian wajah berdasarkan posisi citra wajah yaitu posisi lurus ke depan, rotasi sejajar $15^{\circ} \mathrm{ke}$ kanan, rotasi sejajar $15^{\circ}$ ke kiri, mengangkat dagu $15^{\circ} \mathrm{ke}$ atas dan menunduk kepala $15^{\circ}$ dan berdasarkan tiga jarak objek wajah, yaitu $100 \mathrm{~cm}, 150 \mathrm{~cm}$ dan $200 \mathrm{~cm}$ [3].

Untuk mendeteksi wajah di pose yang berbeda, kumpulan ciri pada Haar dapat diperpanjang dengan memisahkan persegi panjang Haar di beberapa jarak terpisah untuk menangani bidang luar datar rotasi kepala kiri dan kanan [4]. Beberapa karya mengusulkan untuk mengeksplorasi jenis ciri yang lebih homogen dalam rangka meningkatkan kinerja detektor. Namun, memperbanyak ciri dan jenis, otomatis meningkatkan ukuran kumpulan ciri dan mempersempit ukuran penyimpanan [5]-[7].

Ciri umum Haar aslinya ditetapkan dengan ciri persegi panjang diputar $45^{\circ}$ dan ciri mengelilingi tengah untuk menangani rotasi kepala [6]. Sebagai contoh, [8] mengusulkan Edge Orientasi Histogram (EOH) yang dihitung histogram dari tepi orientasi di sub-wilayah jendela tes. Untuk deteksi wajah frontal, EOH untuk mencapai kinerja dengan menggunakan beberapa ratus contoh citra.

Dalam penelitian yang dilakukan metode yang digunakan adalah eksperimen dengan menggunakan haar feature selection untuk mendeteksi sekaligus untuk mengekstraksi ciri pada wajah dan. Metode haar feature selection merupakan bagian dari metode Viola-Jones [9]. Penelitian serupa dengan meningkatkan kemampuan untuk 
melakukan penyekalaan sehingga dapat mendeteksi adanya wajah yang berukuran besar ataupun lebih kecil dari pengklasifikasian pada citra [6].

\section{Metode Penelitian}

Makalah ini disusun melalui tahapan-tahapan sebagai berikut:

\section{1) Penentuan Masalah Penelitian}

Masalah dapat disimpulkan bahwa Metode Haar Feature Selection dapat digunakan untuk mendeteksi wajah manusia. Sedangkan pertanyaan pada penelitian adalah: "Bagaimana Haar Feature Selection dapat mendeteksi wajah dengan berbagai posisi wajah dan jarak yang berbeda?"

2) Penentuan Pendekatan Komputasi

Pendekatan komputasi yang akan digunakan dalam makalah ini adalah metode Haar Feature Selection dimana sampel data dari makalah ini adalah data 5 (lima) posisi citra wajah yaitu posisi miring ke kanan $10^{\circ}$, tegak ke bawah $10^{\circ}$, tegak lurus, tegak ke atas $10^{\circ}$, miring ke kiri $10^{\circ}$ serta 3 (tiga) jarak yang di gunakan setia posisi tersebut. Jarak pertama adalah $30 \mathrm{~cm}$ dari kamera, jarak kedua adalah $49 \mathrm{~cm}$ dari kamera, dan jarak ketiga adalah $55 \mathrm{~cm}$ dari kamera serta 3 (tiga) ukuran piksel yang berbeda.

3) Penerapan Metode

Metode Haar Feature Selection akan diterapkan untuk mendeteksi citra wajah dengan berbagai posisi dan jarak.

4) Evaluasi dan Validasi Hasil Penerapan

Evaluasi dilakukan dengan mengamati hasil pendeteksian citra wajah. Validasi dilakukan untuk dengan melihat akurasi terbaik dari pendeteksian citra wajah dengan berbagai posisi dan jarak.

5) Kesimpulan

Menarik kesimpulan dari keseluruhan proses penyusunan dan pengujian hasil pendeteksian citra wajah.

\section{HASIL DAN PEMBAHASAN}

\section{A. Metode Haar Feature Selection}

Metode Haar Feature Selection merupakan salah satu metode dari metode Viola-Jones. Metode Viola-Jones melakukan pengklasifikasian citra berdasarkan pada nilai ciri yang sedehana. Banyak alasan untuk menggunakan ciri sederhana daripada piksel secara langsung. Alasan paling umum adalah ciri dapat digunakan untuk mengkodekan pengetahuan domain ad-hoc yang sulit dalam pembelajaran terhadap data yang terbatas. Alasan kedua, ciri adalah sistem yang berbasis operasi jauh lebih cepat daripada sistem berbasis piksel [9].

Klasifikasi citra dilakukan berdasarkan nilai dari sebuah ciri. Penggunaan ciri dilakukan karena pemrosesan ciri berlangsung lebih cepat dibandingkan pemrosesan citra perpiksel. Terdapat tiga jenis ciri berdasarkan jumlah Haar yang terdapat didalamnya. Contoh ciri Haar dari metode Viola-Jones diperlihatkan pada Gambar 1 [9].

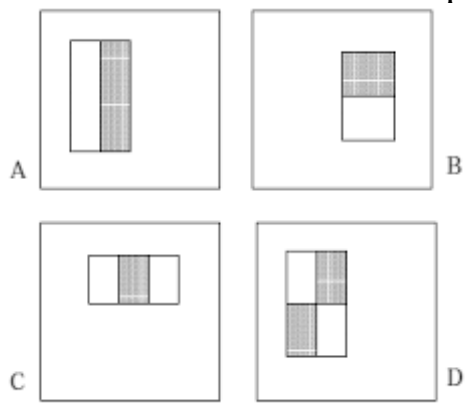

Gambar. 1. Contoh ciri haar pada metode Viola-Jones

Haar Feature Selection sendiri menambah ciri haar yang lebih banyak guna memungkinkan hasil deteksi yang akurat. Contoh ciri Haar yang ada pada metode ini diperlihatkan pada Gambar 2.

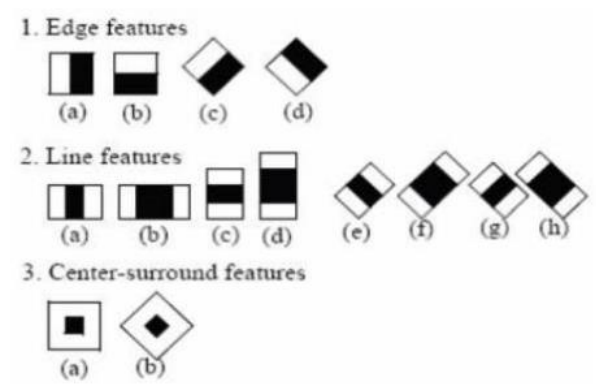

Gambar. 2. Contoh ciri haar pada Haar Feature Selection 
Rumus perhitungan pada metode Haar Feature Selection ditunjukkan pada (1).

$$
F(\text { Haar })=\sum F_{\text {white }}-\sum F_{\text {black }}
$$

Keterangan :

$F($ Haar) : Total nilai ciri

$\sum F_{\text {white }}:$ Nilai ciri pada daerah terang

$\sum F_{\text {black }}:$ Nilai ciri pada daerah gelap

\section{B. Kerangka Sistem}

Kerangka sistem untuk mendeteksi citra wajah menggunakan metode HaarFeature Selection dapat ditunjukkan pada Gambar 3.

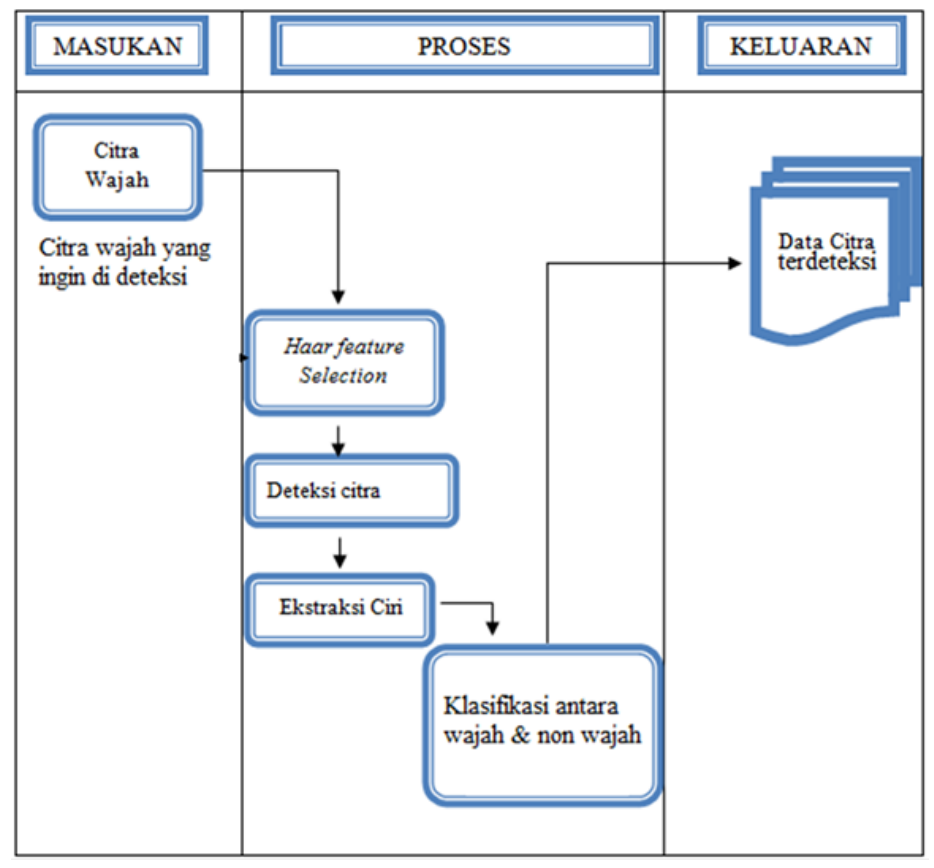

Gambar. 3. Kerangka Sistem

Penjelasan Kerangka sistem untuk deteksi citra wajah menggunakan metode haar feature selection adalah sebagai berikut.

1. Masukan

Pada tahap ini pengguna memasukkan data citra wajah yang ingin di deteksi.

2. Proses

Citra wajah diproses dengan metode haar feature selection agar citra wajah bisa dideteksi, setelah data citra di proses oleh haar feature selection maka proses selanjutnya adalah mengekstraksi ciri dari citra dan akan memisahkan hasil antara wajah dan non wajah

\section{Keluaran}

Setelah semua proses dilakukan maka keluarannya adalah citra wajah yang terdeteksi pada data citra yang sudah dimasukkan ke dalam sistem.

\section{Hasil Eksperimen}

Data sampel dari makalah ini adalah data 5 (lima) posisi citra wajah yaitu posisi miring ke kanan $10^{0}$, tegak ke bawah $10^{\circ}$, tegak lurus, tegak ke atas $10^{\circ}$, miring ke kiri $10^{\circ}$ dan 3 (tiga) jarak serta 3 (tiga) ukuran piksel yang berbeda yang di gunakan setia posisi tersebut. Jarak pertama adalah $30 \mathrm{~cm}$ dari kamera, jarak ke dua adalah $49 \mathrm{~cm}$ dari kamera, dan jarak ke tiga adalah $55 \mathrm{~cm}$ dari kamera.

Citra wajah diambil menggunakan kamera web yang terpansang pada laptop dengan resolusi kualitas tinggi (HD) 1280x720 dengan lima posisi citra dan tiga jarak yang berbeda. Keluaran pada penelitian ini berupa dapat diketahuainya akurasi yang paling baik pada metode Haar Featur Selection untuk citra wajah dengan berbagai posisi citra dan jarak citra yang berbeda. 


\section{a. Pengujian Untuk Deteksi Citra Wajah Dengan Jarak 1}

TABEL I

PENGUJIAN UNTUK DETEKSI CITRA WAJAH DENGAN JARAK 1

\begin{tabular}{ccccc}
\hline \hline $\begin{array}{c}\text { Ukuran } \\
\text { Piksel }\end{array}$ & $\begin{array}{c}\text { Waktu } \\
\text { Deteksi } \\
\text { (detik) }\end{array}$ & Akurasi & $\begin{array}{c}\text { Wajah } \\
\text { Terdeteksi }\end{array}$ & Keterangan \\
\hline 120x120 & 0,63 & $68,57 \%$ & Ya & Terbaik \\
120x190 & $\mathbf{0 , 6 5}$ & $\mathbf{8 4 , 4 4 \%}$ & Ya & \\
$120 \times 250$ & 0,67 & $81,43 \%$ & Ya & \\
\hline \hline
\end{tabular}

Seperti terlihat pada Tabel I, pengujian deteksi citra wajah dengan jarak $30 \mathrm{~cm}$ menghasilkan akurasi terbaik sebanyak 84,44\% dengan waktu 0,65 detik pada skala citra 120x190 piksel.

b. Pengujian Untuk Deteksi Citra Wajah Dengan Jarak 2

TABEL II

PENGUJIAN UNTUK DETEKSI CITRA WAJAH DENGAN JARAK 2

\begin{tabular}{|c|c|c|c|c|}
\hline $\begin{array}{c}\text { Ukuran } \\
\text { Piksel }\end{array}$ & $\begin{array}{c}\text { Waktu } \\
\text { Deteksi } \\
\text { (detik) }\end{array}$ & Akurasi & $\begin{array}{c}\text { Wajah } \\
\text { Terdeteksi }\end{array}$ & Keterangan \\
\hline $120 \times 120$ & 0,66 & $77,41 \%$ & $\begin{array}{c}2 \text { wajah } \\
\text { tidak } \\
\text { terdeteksi }\end{array}$ & \\
\hline $120 \times 190$ & 0,64 & $89,20 \%$ & Ya & Terbaik \\
\hline $120 \times 250$ & 0,61 & $73,61 \%$ & $\mathrm{Ya}$ & \\
\hline
\end{tabular}

Pada Tabel II, pengujian deteksi citra wajah dengan jarak $49 \mathrm{~cm}$ menghasilkan akurasi terbaik sebanyak 82,20\% dengan waktu 0,64 detik pada skala citra 120x190 piksel. Akan tetapi ada dua citra yang tidak bisa di deteksi yaitu pada skala 120x120 piksel dengan posisi Miring ke kanan $10^{\circ}$ dan Miring ke kiri $10^{\circ}$ dikarenakan penyekalaan terlalu kecil.

\section{c. Pengujian Untuk Deteksi Citra Wajah Dengan Jarak 3}

TABEL III

PENGUJIAN UNTUK DETEKSI CITRA WAJAH DENGAN JARAK 2

\begin{tabular}{ccccc}
\hline \hline $\begin{array}{c}\text { Ukuran } \\
\text { Piksel }\end{array}$ & $\begin{array}{c}\text { Waktu } \\
\text { Deteksi } \\
\text { (detik) }\end{array}$ & Akurasi & $\begin{array}{c}\text { Wajah } \\
\text { Terdeteksi }\end{array}$ & Keterangan \\
\hline $120 \times 120$ & 0,59 & $77,92 \%$ & $\begin{array}{c}\text { 1 wajah } \\
\text { tidak } \\
\text { terdeteksi }\end{array}$ & Terbaik \\
$\mathbf{1 2 0 x 1 9 0}$ & $\mathbf{0 , 6 1}$ & $\mathbf{9 1 , 3 4 \%}$ & Ya & Ya \\
$120 \times 250$ & 0,65 & $85,91 \%$ & Ya & \\
\hline \hline
\end{tabular}

Dengan jarak $55 \mathrm{~cm}$ pengujian deteksi citra wajah sebagaimana terlihat pada table III menghasilkan akurasi terbaik sebanyak 89,34\% dengan waktu 0,61 detik pada skala citra 120x190 piksel. Akan tetapi ada satu citra yang tidak bisa di deteksi yaitu pada skala 120x120 piksel dengan posisi Tegak ke atas $10^{\circ}$ penyekalaan terlalu kecil.

Berdasarkan hasil pengujian deteksi citra wajah pada jarak 1, jarak 2 dan jarak 3 dengan masing-masing jarak diuji lagi dengan 5 (lima) posisi yang berbeda dan 3 (tiga) piksel yang berbeda maka didapatkan hasil terbaik dari uji deteksi citra wajah dengan metode Haar Feature Selection yaitu pada jarak ke 3 pada 120x190 piksel dan waktu deteksi 0,61 detik dengan akurasi mencapai 91,34\%.

\section{KESIMPULAN}

Dari penetilian menggunakan metode Haar Feature Selection untuk deteksi citra wajah manusia diperoleh kesimpulan sebagai berikut.

1. Menggunakan metode Haar Feature Selection untuk mendeteksi citra wajah manusia metode ini menghasilkan akurasi deteksi terbaik yaitu pada jarak ke 3 dan 120x190 piksel dengan waktu deteksi 0,61 detik dengan akurasi mencapai 91,34\%.

2. Proses penyekalaan pada proses prapengolahan berperan penting untuk metode haar feature selection untuk mencari piksel citra wajah, dikarenakan semakin kecil citra wajah maka semakin cepat metode haar feature selection melakukan proses perhitungan piksel pada suatu citra tetapi semakin banyak juga ciri dari citra tersebut yang hilang 
3. Tidak semua citra wajah bisa di deteksi secara baik oleh program dikarenakan proses deteksi citra wajah yang ingin di deteksi masih bergantung pada jarak, intensitas cahaya dan posisi dari masing-masing citra yang di ambil

\section{DAFTAR PUSTAKA}

[1] J. Zhang, N. Ji, J. Liu, J. Pan, and D. Meng, "Enhancing performance of the backpropagation algorithm via sparse response regularization," Neurocomputing, vol. 153, pp. 20-40, 2015.

[2] K. Padmaja and T. N. Prabakar, "FPGA based real time face detection using Adaboost and histogram equalization," Int. Conf. Adv. Eng. Sci. Manag. (ICAESM 2012), Nagapattinam, Tamil Nadu, pp. 111-115, 2012.

[3] H. Santoso and A. Harjoko, "Haar Cascade dan Adboost.pdf." 2013.

[4] S. Z. Li and Z. Q. Zhang, "FloatBoost learning and statistical face detection," IEEE Trans. Pattern Anal. Mach. Intell., vol. 26, no. 9, pp. 1112-1123, 2004.

[5] T. Mita, T. Kaneko, and O. Hori, "Joint Haar-like features for face detection," Proc. IEEE Int. Conf. Comput. Vis., vol. II, pp. 1619-1626, 2005.

[6] R. Lienhart and J. Maydt, "An extended set of Haar-like features for rapid object detection," 2003.

[7] M. T. Pham and T. J. Cham, "Fast training and selection of Haar features using statistics in boosting-based face detection," Proc. IEEE Int. Conf. Comput. Vis., 2007.

[8] K. Levi and Y. Weiss, "Learning object detection from a small number of examples: the importance of good features," pp. 53-60, 2004.

[9] P. Viola and M. Jones, "Rapid object detection using a boosted cascade of simple features," no. July 2014, pp. I-511I-518, 2005. 
JTIULM - Volume 04, Nomor 1, April 2019: 7 - 12 